\title{
Responsibly Including Survivors' Voices in the Planning and Implementing of Educational Programmes for Healthcare Providers
}

Preeti Panda, Annette Mango, and Anjali Garg

Please cite this article as: P Panda, A Mango, and A Garg, 'Responsibly Including Survivors' Voices in the Planning and Implementing of Educational Programmes for Healthcare Providers', Anti-Trafficking Review, issue 17, 2021, pp. 148-153, https://doi.org/10.14197/atr.2012211710

That feeling was amazing... a room full of educated doctors were looking to me for my input and advice. I felt so proud of the progress I have made and where I have come. - Annette Mango's reflections about our educational intervention

\section{Introduction}

Over the last several years, the call for incorporating survivor voices into human trafficking education for healthcare providers has grown, with assessment tools to provide guidance on seeking survivor input as a key component. ${ }^{1} \mathrm{~A}$ recent systematic review of the literature found that only two published educational interventions had partnered with survivors during the development of trainings. ${ }^{2}$

1 CL Miller, G Duke, and S Northam, 'Child Sex-Trafficking Recognition, Intervention, and Referral: An educational framework for the development of health-care-provider education programs', Journal of Human Trafficking, vol. 2, issue 3, 2016, pp. 177-200, https://doi.org/10.1080/23322705.2015.1133990; S Lockyer, 'Beyond Inclusion: Survivor-leader voice in anti-human trafficking organizations', Journal of Human Trafficking, 2020, pp. 1-22, https://doi.org/10.1080/23322705.2020.1756122; C Miller et al., 'Health Care Provider Human Trafficking Education: Assessment tool', Laboratory to Combat Human Trafficking and HEAL Trafficking, 2018.

2 H Fraley, T Aronowitz and H Stoklosa, 'Systematic Review of Human Trafficking Educational Interventions for Health Care Providers', Western Journal of Nursing Research, vol. 42, no. 2, 2020, pp. 131-142, https://doi.org/10.1177/0193945919837366. 
While many professionals in the field are aware of the importance of survivor partnerships, translating this awareness into action is not always straightforward. Organisations that hope to create a survivor-informed educational intervention face difficulties in responsibly partnering with survivors as human trafficking consultants, and meaningfully incorporating their input into trainings. ${ }^{3}$

In this paper, we describe the processes and best practices of establishing partnerships between healthcare providers and trafficking survivors in the development of an educational curriculum on human trafficking for paediatric healthcare providers.

\section{Survivor-informed Educational Curriculum and Intervention}

We implemented an educational intervention to increase knowledge and awareness of human trafficking amongst paediatric physicians in training at a children's hospital in an urban location in the United States. The leadership team of this intervention included two resident physicians, an attending physician, a paediatric sexual assault nurse examiner, and a motivational speaker who was also a local survivor of human trafficking and human trafficking consultant. Since we were the few professionals at our hospital who were openly interested in anti-trafficking work, this team came together organically in order to coordinate our efforts to serve trafficked children. The two resident physicians had initially created a framework for the content of the educational curriculum. The human trafficking consultant's contribution included review of the content for accuracy, input on their personal experiences with the healthcare system during and after being trafficked, and tangible ways to improve sensitivity of care when interacting with patients who may be victims of trafficking. We implemented the intervention as four hour-long educational sessions, and the survivor was compensated for their time as an expert consultant. ${ }^{4}$

\section{Establishing Survivor Partnerships}

\section{Utilisation of Community Resources}

There are several avenues that can be pursued when seeking to establish a responsible survivor partnership to inform an educational programme. One

3 Note, there are existing survivor-led organisations already engaged in anti-trafficking work.

4 L Powers and N Paul, 'The Need for Survivor-informed Research to Fight Human Trafficking', Delta 8.7, 1 November 2018, retrieved 27 May 2021, https://delta87. org/2018/11/need-survivor-informed-research-fight-human-trafficking. 
avenue is utilising community resources from the local area. Organisations working with survivors of trafficking may be in contact with survivor leaders who may be willing to partner as consultants. ${ }^{5}$ Community organisations may also have peer mentorship or leadership development groups for survivors that can serve as a resource. In our partnership we approached a survivor through a community organisation that facilitated a leadership development programme for survivors. The human trafficking consultant had previous experience speaking to local healthcare professionals and was continuing in group and mental health therapy to support their own well-being. Involving a local survivor on the leadership team served as an opportunity to provide more context through their experiences with the community's health services. Resources at the state or national level may be utilised to form survivor partnerships as well. In the United States, these resources include state-wide human trafficking coalitions and country-wide networks such as the National Survivor Network. ${ }^{6}$

\section{Establishment of Equal Partnership}

After including the human trafficking consultant, who was also a survivor, into the intervention, the team needed to establish the roles and expectations of each team member and ensure that the survivor is seen as an equal partner. Our equitable partnership was modelled after the 'patient advisory councils' implemented in primary healthcare settings that offer a 'best practice guidance' for creating survivor-informed programming, where survivor consultants are invited to join organisational leadership such as trafficking clinic advisory boards. ${ }^{7}$ At the outset, the human trafficking consultant and physician team members discussed a clear vision of the intervention and the survivor's desired level of involvement. These expectations were created collaboratively, and emphasis was placed on autonomy, empowerment, and reduction of re-traumatisation through trauma-informed approaches. ${ }^{8}$ Through these discussions, the human trafficking consultant

5 See footnote 3 .

6 National Survivor Network, retrieved 10 November 2020, https:// nationalsurvivornetwork.org.

7 A Sharma et al., 'How Can We Talk about Patient-centered Care without Patients at the Table? Lessons learned from patient advisory councils', The Journal of the American Board of Family Medicine, vol. 29, no. 6, 2016, pp. 775-784, https://doi.org/10.3122/ jabfm.2016.06.150380; R Chambers, J Cox, and H Austin Gibbs, Mercy Family Health Center, Human Trafficking Medical Safe Haven Program and Shared Learnings Manual, Dignity Health, 2019; National Human Trafficking Training and Technical Assistance Center, 'Toolkit: Survivor-informed practice self-guided assessment', 2017, https://nhttac. acf.hhs.gov/resources/toolkit-survivor-informed-practice-self-guided-assessment.

8 U.S. Department of State Office to Monitor and Combat Trafficking in Persons, 'Engaging Survivors of Human Trafficking: Fact sheet', 27 June 2017, https://www. state.gov/engaging-survivors-of-human-trafficking. 
disclosed their comfort and desire to help not only with the curriculum planning but also with delivering the presentation. In addition to compensating the survivor for serving as a human trafficking consultant, we continually sought their input, debriefed them to prevent or assess any re-traumatisation, avoided sensationalising experiences, and protected their confidentiality when necessary. The emphasis throughout this professional relationship was that of an equitable partnership, and the survivor's suggestions and concerns were given equal consideration to those of the other leadership members. Due to limited resources to include additional human trafficking consultants, our team reconciled and incorporated into our programme the perspective that survivors of human trafficking have a myriad of complex experiences within the healthcare system.

Central to establishing an equal partnership is ensuring that the survivor is not just invited to share their story, but also given a voice throughout the development and implementation of the intervention. In our intervention, the physicians and human trafficking consultant met to discuss each educational content area during the phase of curriculum development. Each presentation slide was reviewed with the survivor, and modifications or additional points of emphasis were adjusted based on their input. Additionally, the human trafficking consultant was given autonomy to decide which portions of the presentation they would speak about, and whether or not they wanted to share personal experiences.

In taking these collaborative steps to create an equitable partnership, the intervention resulted in improved knowledge and understanding for the physician leaders of a survivor's experience within the healthcare system, and improved understanding for the human trafficking consultant as to how healthcare providers view patient care. The consultant's input led to tangible changes in how the educational content was delivered. For example, following discussions regarding their experiences with the healthcare system, sections on communicating with potentially trafficked children were modified to emphasise empathy and kindness. The importance of provider discretion and severe consequences for breaches in confidentiality, as well as realising the impact of routine medical practices on those who have experienced complex trauma were, amongst others, important changes to the standard educational content that resulted from this equitable partnership.

\section{Reflections on Equitable Partnership}

Below are reflections from the team regarding the most important takeaways, challenges, and successes resulting from working towards the creation of an equitable partnership to create this healthcare educational intervention.

Annette: Working as a human trafficking consultant allowed me to feel empowered about a period in my life when power had been stripped from me. While I was not previously trained to be a consultant, my training and experience in motivational 
speaking allowed me to give voice to the traumas that I experienced, and to put in perspective all that I had gone through, specifically about how the healthcare system played a role in continuing my cycle of exploitation. However, being a consultant to this educational intervention was difficult and challenging as well. I am thankful for the counselling I was engaged in prior to and throughout the period of consultancy. I am thankful to the support group that I was a part of for giving me strength and space to process the traumas that I had been through. This whole experience was challenging, but I wanted to and had to challenge myself so that I could continue to heal. I encourage other survivors to be consultants, but also to recognise that they need to be in a supportive space to be able to process their trauma. This experience left me feeling strong and empowered. I was able to stand up in front of a group of professionals, tell them about my story, and educate them on how to be better providers for other survivors. That felt good. My advice to any professionals that are putting on this educational intervention: be protective of your survivor, continue to engage with them on how much they want to be involved in, and be kind. Be kind. Be kind. Be kind.'

Anjali: 'Initially, I was worried about re-traumatising Annette. Given that this topic personally affected them and was in part a discussion of their trauma, we wanted to give them freedom to be involved as deeply or as superficially as they wanted. I am thankful for how inspiring and engaged Annette was, and that they continued therapy and group sessions throughout our endeavour. Ensuring the human trafficking consultant is continuing their own healing process is very important. After each session, we debriefed with Annette to ensure that no part of the process had been triggering, re-traumatising, or emotionally draining. These conversations were invaluable, and taught us the power of Annette's resilience.'

Preeti: 'A challenge in creating an equal partnership was navigating power dynamics. How could we co-lead and co-facilitate this programme and ensure that the physicians in the team did not explicitly or implicitly overshadow Annette's voice? How could we ensure that Annette felt comfortable sharing opinions not just with us, but with other doctors we would be educating? We sought to overcome this challenge through openly discussing these concerns with Annette to set the expectation that we were all leaders in the intervention. We then scheduled regular in-person meetings so that all of us were at the table when important decisions were being made. We also re-visited this issue during debriefing sessions to understand Annette's feelings on co-leading the intervention and speaking to the group.' 


\section{Moving Towards Equitable Collaboration}

Involvement of survivors as human trafficking consultants can enhance educational interventions for healthcare providers. However, engagement with survivors requires practitioners to be responsible and accountable for the effects of this involvement. Teams hoping to create a more equitable collaboration can take several actions, starting with ensuring that the survivor is treated as an expert and compensated as such. Survivors should be allowed ample space and autonomy over the nature of their involvement and given equal opportunities to contribute to the formulation and implementation of the educational curriculum. Furthermore, an open dialogue among team members to prevent re-traumatisation and overcome power dynamics can be facilitated through regular meetings with all team members, debriefing after implementation, and continually seeking input and feedback from one another. Only through the provision of an equal and collaborative platform can we aim to mitigate the cycle of exploitation.

Preeti Panda is a paediatric emergency medicine fellow physician at Stanford University, and completed her residency training at Rainbow Babies and Children's Hospital in Cleveland, Ohio. Her experiences working directly with trafficked high school students sparked a passion for addressing the health needs of this population. This led her to pursue anti-trafficking programming and research during her medical training, eventually establishing a medical clinic to treat child trafficking survivors along with Anjali. She continues to work with survivors on creating trauma-informed healthcare programmes to better serve trafficked children.Email: preetipanda2017@gmail.com

Annette Mango is a motivational speaker and survivor leader. She completed a Survivor-Educator Certification Course through the Renee Jones Empowerment Center in 2017, and participates in survivor groups, peer mentorship, and speaking engagements. She is interested in educating professionals on human trafficking and how to engage survivors in a trauma-informed manner.

Anjali Garg is a paediatric critical care fellow physician at Johns Hopkins Children's Center. She completed her paediatric residency training at Rainbow Babies and Children's Hospital in Cleveland, Ohio, during which time she researched the role of the healthcare provider in the identification and intervention of trafficked children. Anjali and Preeti subsequently opened a medical home for child trafficking survivors. Her passion to care for those who have been afflicted by the complex trauma seen in human trafficking led Anjali to pursue a career in critical care. She continues to work towards providing healthcare in a trauma sensitive manner and works to empower survivors in her medical practice. Email: anjaliga07@gmail.com 